\title{
An Integrated Approach to Address Endemic Fluorosis in Jharkhand, India
}

\author{
Luke H. MacDonald ${ }^{1}$, Gopal Pathak ${ }^{2}$, Burton Singer ${ }^{3}$, Peter R. Jaffé ${ }^{4 *}$ \\ ${ }^{1}$ Global Water Program, Johns Hopkins University, Baltimore, USA \\ ${ }^{2}$ Environmental Science and Engineering Group BIT, Mesra Ranchi, India \\ ${ }^{3}$ Emerging Pathogens Institute, University of Florida Gainesville, Gainesville, USA \\ ${ }^{4}$ Department of Civil and Environmental Engineering, Princeton University, Princeton, USA \\ E-mail: Jaffe@princeton.edu \\ Received April 5, 2011; revised May 9, 2011; accepted June 17, 2011
}

\begin{abstract}
This paper presents the grounds for an integrated approach to address endemic fluorosis in Jharkhand, India, an approach that encompasses health monitoring, community-based water systems management, and locally synthesized hydroxyapatite, a sustainable water treatment technology. The results of this study, focusing on kinetics and sorption isotherms, demonstrate that an inexpensive, locally synthesized hydroxyapatite effectively removes fluoride from water and that the Dean Index, a measure of dental fluorosis, of school children provides a sensitive, rapid biometric to track the success of a fluoride water treatment intervention. Previous efforts to manage the fluoride problem in Jharkhand were unsuccessful, largely due to lack of accountability and inadequate community involvement. This paper explores how integrating the production of a locally synthesized hydroxyapatite with community health monitoring via the Dean Index fits into a management strategy with robust accountability mechanisms and community participation that, as historical examples suggest, is likely to succeed in Jharkhand.
\end{abstract}

Keywords: Community Participation, Dean Index, Fluoride, Fluorosis, Hydroxyapatite, Rural Water Supply

\section{Introduction}

There are three billion people living in rural areas of developing countries, of which $28 \%$ lack access to improved water sources due, in part, to a lack of appropriate technological and policy solutions [1,2] Although scientists, NGOs, governments, and corporations have made much progress in evidence-based treatment solutions for some of these problems, development of solutions to many others lag far behind. Fluoride in drinking water is one such straggling problem that needs a demonstrably successful technological solution alongside an effective implementation policy to ensure drinking water quality that improves health, backed up by health and chemical data.

Today, the water community cannot ignore demand for a robust solution for fluoride. At least 25 countries contain populations with water supplies that have unsafe levels of fluoride, and, while the worldwide number of people suffering from fluorosis is not known, some put the at-risk population at 200 million, with 70 million in
India and 45 million in China alone [3-5]. Communities consume water with double or even twenty times the recommended fluoride limit [3], and recent surveys continue to find new areas with high fluoride concentrations [6-8]. Doubtless, the number of people at risk for fluoride related problems will rise as more people living in dry regions turn to deep bore wells for drinking water in an increasingly warmer and dryer global climate [9].

High fluoride intake results in two physically visible forms of disease, dental fluorosis and skeletal fluorosis. Mild forms of skeletal fluorosis include weak bones that break easily, while severe forms manifest as spine degeneration or acutely soft bones that bend dramatically and painfully, especially in the leg [10]. Fluorosis often precludes the ability to work, driving suffering individuals and their families deeper into poverty. Other problems associated with high fluoride intake include damage to the kidney, liver, brain, and cancer [11-14].

Like the better-known problem of arsenic in groundwater, fluoride occurs naturally in groundwater, and the most commonly used methods to remove it are chemical 
filtration and precipitation [15-17]. The only substantial difference between a fluoride solution and an arsenic solution for contaminated drinking water might be the choice of filter media, owing to inherent differences in chemistry and owing to the relatively higher fluoride concentration. While both are often present at concentration five to ten times the drinking water limit, the limit for fluoride is one hundred fifty times higher on a mass basis, $1.5 \mathrm{ppm}$ for fluoride versus $0.01 \mathrm{ppm}$ for arsenic [18], and nearly six hundred times higher on a molar basis. Hence, the amount of fluoride that a filter must remove in areas with high fluoride in drinking water is many orders of magnitude higher than the amount of arsenic that a filter must removes in areas with high arsenic in drinking water. Therefore, the challenge that the water community faces is to design a fluoride filter that operates for a reasonable time period at a sustainable cost. This technical problem and a relative dearth of studies of fluoride in drinking water has led to a situation in which rural fluoride interventions, unlike arsenic interventions, have yet to produce any long-term successes.

Most past efforts to implement sorption and precipitation techniques to treat water for fluoride in rural India have eventually failed [19]. Few field-tested technologies effectively remove fluoride. For example, consider the sorption capacity of fluoride on active alumina near neutral $\mathrm{pH}$; the Langmuir maximum monolayer sorption capacity of fluoride on active alumina in distilled water [20] is $2.41 \mathrm{mg} / \mathrm{g}$, versus the $9.93 \mathrm{mg} / \mathrm{g}$ for arsenate on active alumina [21], which means that active alumina is far less effective at removing fluoride for drinking purposes, especially given the comparably higher concentration of fluoride in groundwater discussed above. In addition to these technological problems, many past efforts to defluoridate water in India were not well-suited to the social context of the problem, costing too much or requiring materials that were difficult to come by in rural settings, and outsiders too often deployed technologies without active community involvement [19].

This research aims to demonstrate that synthetic hydroxyapatite can remove fluoride cheaply and effectively in poor, rural settings using locally available materials for synthesis. The mineral hydroxyapatite is the major component of our teeth and bones, and it transforms to fluorapatite, a softer mineral, when in contact with dissolved fluoride [22]. That transformation is one of the reasons fluoride weakens bones and can both help or harm teeth; thin layers of fluoroapatite prevent bacterially driven tooth decay, but thick layers lead to soft, pitted teeth [22]. While researchers recognize that hydroxyapatite holds potential as a possible solution to the fluoride problem [17,23], no study has attempted to demonstrate fluoride removal with hydroxyapatite produced from in- expensive, low-grade materials available locally in rural areas afflicted with high fluoride.

Finding a new low cost solution is particularly important in India because some more common low cost production methods are not appropriate. Hydroxyapatite substrate can be made from bone char, but consuming water filtered with animal bones conflicts with religious and culture taboos in India. As an alternative treatment, we demonstrate proof of the principle that inexpensive, locally synthesized hydroxyapatite from inorganic ingredients is a practical and viable filter media, scalable to communities of any size.

A second goal of this research is to build links between the health community and the water community, an undersold concept in many water-based projects [24]. The underlying goal of improved water supplies is improved health, but research in the water community too often focuses on technical success and does not address whether water interventions improve health. Healthbased targets for fluorosis makes sense, since there are other pathways of fluoride exposure, such as food or tea, and treating the water supply will not reduce fluoride intake through these pathways [5,25,26]. By laying out baseline measurements of fluorosis in the community for a case study, this research creates the benchmark for future success in the community under study and proposes a framework for integrating regular health surveys into a fluoride intervention program.

The third major goal of this paper is to explore past and future water systems management choices for the state of Jharkhand, India, which serves as the platform for this research. In the northwest districts of Palamu and Garhwa, fluoride in groundwater poses a significant challenge. In 2003, UNICEF and the Birla Institute of Technology surveyed water sources throughout these districts for fluoride and found 833 of 3775 (22\%) of water sources in Garhwa above the Indian permissible limit of 1.0 ppm, and 560 of 2864 water sources (20\%) in Palamu above the fluoride limit (see Figure 1, and Pathak, et al. 2005) [7]. Multiplying the percent of water sources affected by the raw populations, one finds that the districts of Garhwa and Palamu, at 1.1 and 2.1 million people, respectively (Census of India, 2005), hold a combined total of 662,000 people at risk for consuming water with unsafe levels of fluoride to first approximation. Compared to the rest of India, households in Palamu and Garhwa are poor and have a lower level of literacy (Table 1). A high level of food insufficiency exists in Palamu (Table 1), and both areas are well-known hotspots of extremist violence [27]. A fluoride mitigation program that is robust enough to succeed in these areas is 


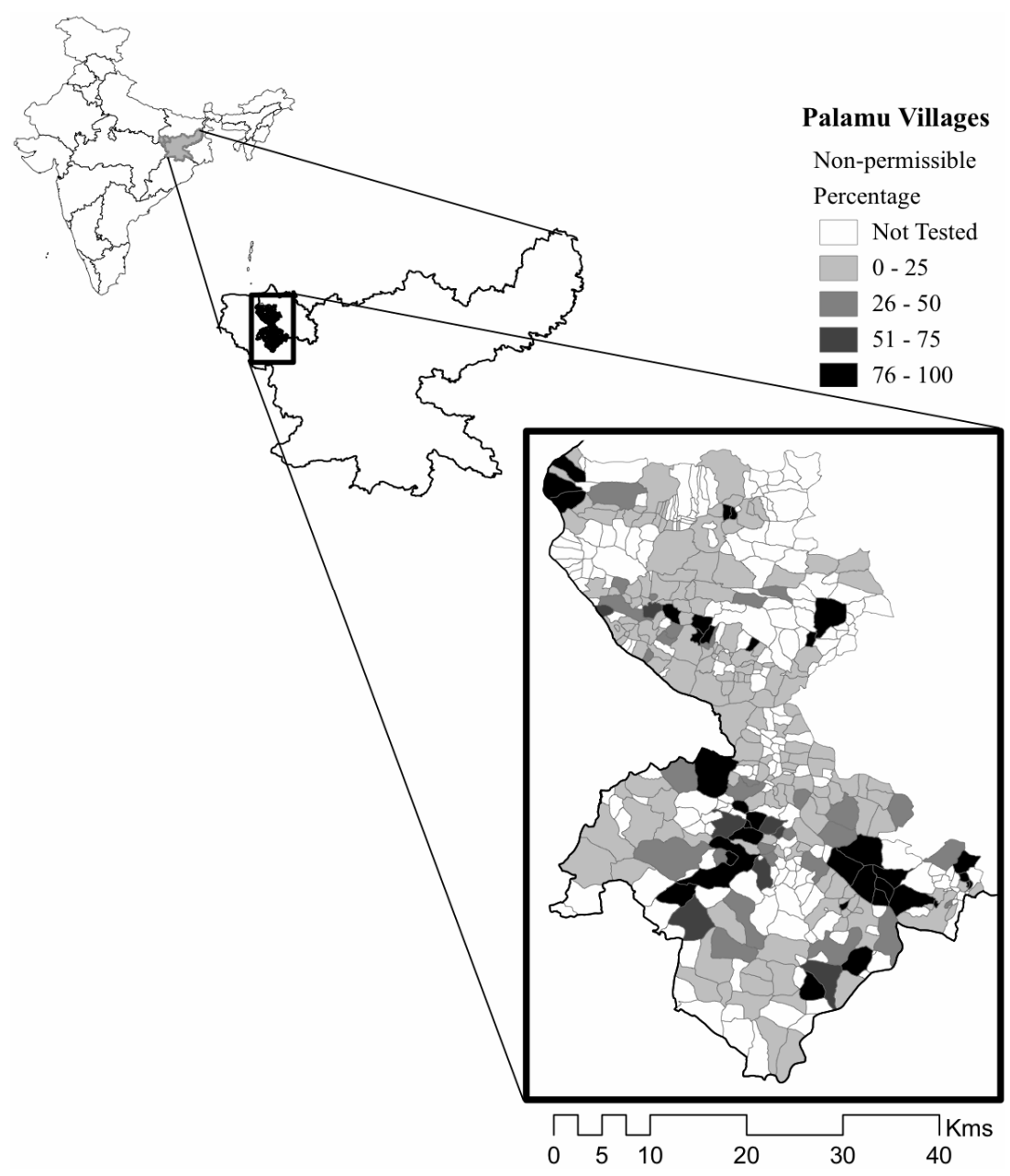

Figure 1. Results of a 2005 fluoride survey of villages in western Palamu, shown in reference to the state of Jharkhand, and India (ArcGIS data courtesy of G. Pathak, [7]). Here, shading indicates the percent of water sources tested in a village with fluoride concentrations above $1.0 \mathrm{ppm}$, the permissible limit in India (Hach fluoride field kit). No water sources were tested in villages shaded in white. This map shows that the fluoride problem is clustered in many parts of the district, motivating the need for an integrated approach to sustain a water treatment program over a diverse geography.

Table 1. Select demographic statistics for Palamu and Garhwa, the districts under study, compared to the state average and the national average. Poverty headcount ratio is defined as the percent of households living below the poverty line, adjusted for that area and urban/rural economies. Both Palamu and Garhwa are poorer and less educated than the rest of India. The high rate of food insufficiency in Palamu suggests that nutritional deficiencies, especially low calcium intake, in Palamu may contribute increase fluorosis risk, as in other areas [10]. Data are from the NSSO 61st round (2004-2005).

\begin{tabular}{cccc}
\hline & \% Poverty & \% Literacy & $\begin{array}{c}\text { \% Households without } \\
\text { two square meals/day }\end{array}$ \\
\hline Palamu & 53.4 & 56.56 & 23.45 \\
Garhwa & 32.2 & 58.95 & 0 \\
Jharkhand & 33.15 & 58.82 & 0.57 \\
India & 21.76 & 67.3 & 1.93 \\
\hline
\end{tabular}

likely to succeed elsewhere.

\section{Methods}

\subsection{Synthesis, Kinetics, and Isotherms}

This study tested the sorption kinetics and capacity for fluoride removal of two different types of hydroxyapatite in artificial groundwater, referenced against the sorption capacity of active alumina (General Carbon Corp, NJ). All experiments used artificial groundwater media modeled after real groundwater data from an area near villages afflicted with high fluoride in Jharkhand, India, matching representative alkalinity, hardness, total dissolved solids, and $\mathrm{pH}$, with $4 \mathrm{mM} \mathrm{NaHCO} 3,0.3 \mathrm{mM}$ $\mathrm{KNO}_{3}, 0.75 \mathrm{mM} \mathrm{NaSO}_{4}, 2.2 \mathrm{mM} \mathrm{CaCl}$, and $1 \mathrm{mM} \mathrm{MgCl}$ [28], a recipe in agreement with groundwater chemistry 
in other fluoride afflicted regions (see, for example, Das, et al. [29]). The resulting solution was at $\mathrm{pH} 6.5 \pm 0.2$. Equilibrium sorption results with deionized water and sodium fluoride alone achieved similar results for select samples.

Pure hydroxyapatite, synthesized according to Verwilghen et al. [30], serves as a reference material here. Synthesis of low-grade hydroxyapatite formed from materials in Jharkhand, India, is possible using a variant of this method. In this case, vigorously mixing $5 \mathrm{Kg}$ of market available lime $(\mathrm{CaO})$ with $100 \mathrm{~L}$ of groundwater by hand while adding $85 \%$ - $90 \%$ phosphoric acid at a rate of approximately $50 \mathrm{~mL} / \mathrm{min}$ produced a low-grade hydroxyapatite. These low-grade samples were dried at $250^{\circ} \mathrm{C}$ to form hard particles suitable for a filter bed, ranging in size from $\sim 0.1$ to $2 \mathrm{~mm}$. XRD analysis confirmed the presence of hydroxyapatite in the samples made from market available materials (KT GeoServices, Texas, USA). Porosity and bulk density of all samples were measured in a graduated cylinder by adding known masses to precise volumes of water. Measuring the bed volume and total volume allows inference of pore volume and bulk density. Clear Science, Inc, Minnesota, performed BET surface area measurements of hydroxyapatite while the manufacturer reported BET surface area of active alumina.

\subsection{Hypothetical Filter Performance and Breakthrough Calculations}

To predict the long-term field performance of the filter one can use simple 1-dimenionsal transport models. As discussed above, sorption is fast compared to the flow rates, which justifies the use of equilibrium models to predict breakthrough. Setting the population to 700 persons, the approximate size of the high fluoride village in Palamu, with per capita water consumption at $5 \mathrm{~L}$ /day and inflow concentration at $10 \mathrm{ppm}$ fluoride, a high estimate for this region, one can gain a conservative estimate of the filter life. Standard 1-dimensional transport equations apply to community filters filled with active alumina or granular hydroxyapatite.

To determine whether dispersion is significant, this research included a breakthrough analysis with a linear isotherm on activated alumina, which showed that neglecting dispersion diminished the breakthrough time by less than 4\%. Therefore, calculations in this study do not take dispersion into account, and instead employ analytical solutions to the advective transport equation for empirically fitted sorption isotherms for active alumina and hydroxyapatite, testing for best fit using both linear and nonlinear sorption models.

This study considers nonlinear sorption in the form of
Langmuir and Freundlich isotherms, conditions for which Sheng and Smith [31] demonstrate that discontinuities develop in the concentration profile, i.e. shock fronts, under continuous injection when the Freundlich isotherm parameter $m$ is less than one, or when the Langmuir isotherm applies. Under continuous contaminant injection into an initially uncontaminated media, they report the following equations describe shock front velocity for Freundlich and Langmuir isotherms, respectively:

$$
\begin{gathered}
v_{F}=\frac{v}{1+\frac{\rho K_{f} C_{o}^{m-1}}{n}} \\
v_{L}=\frac{v}{1+\frac{\rho a S_{m}}{n\left(1+a C_{o}\right)}}
\end{gathered}
$$

Here, $v$ is the linear velocity of water, $\rho$ is the bulk density of the sorbent, $n$ is the porosity, $C_{o}$ is the influent concentration, and $v_{F}$ and $v_{L}$ are the shock front velocities under Freundlich and Langmuir sorption, respectively. Breakthrough times are simply the designed filter length, $L$, divided by the shock front velocity:

$$
t_{\text {breakthrough }}=\frac{L}{v_{F}} \text {, or } \frac{L}{v_{L}} .
$$

\subsection{Community Health Survey in Palamu}

The Dean Index is a widely used tool that quantifies the severity of dental fluorosis in an individual on a scale from 0 to 4 according to simple morphological metrics [32]. Teeth with opaque white flecks spotting less than $25 \%$ of the tooth score a 1 , for example, while brown, severely degraded, and pitted teeth score a 4 . The research in this paper employed the Dean Index to quantify dental fluorosis at three schools in rural Jharkhand, hereafter referred to as schools $A, B$, and $C(\mathrm{~N}=50,43,40)$. These schools were all tuition-free public schools that were representative of rural Jharkhand with socio-economic characteristics, as summarized in Table $\mathbf{1 .}$

The main difference between these three locations was the fluoride concentration of their water supply. The home water supply of students at schools $A$ and $B$ had high fluoride, estimated at a mean of $4.7 \pm 2.4 \mathrm{ppm}$ and $2.3 \pm 2.2$ ppm, respectively, while at school $C$ all measured water sources exhibited fluoride concentrations below $1 \mathrm{ppm}$. The age distribution of children in our study is shown in Figure 4. Sample days took place neither on religious nor secular holidays. In school $A$, all children present in the school on the day of our visit were included in the study ages 5 - 14 (50 of an estimated 175, 
based on teacher response). In school B, all children age 9 - 14 present were included (43 of an estimated 100, based on teacher response). In school $\mathrm{C}$ we have a representative sample of those present (40 of an estimated 300 , based on teacher response).

To estimate the Dean Index, surveyors used a simple examination of the front upper and lower teeth while children smiled, a technique that tends to underestimate the Dean Index [32], because a full dental exam was not feasible in this setting. Surveyors worked in pairs, and anonymous, numbered photos of teeth were collected as validation of field observations. In addition to the dental exam, field teams collected data on gender, age and, for a subset of subjects at each school, the fluoride concentration of the home water source. Surveyors were blind to the children's home fluoride concentration. The mean fluoride concentration for school $A$ is based on a subset of 41 students' home water source, while the mean fluoride concentration at school $B$ derives from 20 students' source, and 30 students' water source at school $C$. All field fluoride concentration values came from measurements on an ion-selective fluoride probe (Hach).

A generalized linear model of Dean Index regressed against age, gender, and home fluoride concentration was fit to data at school $A$ (statistical software package JMP 7.0, SAS corp, USA). Such regression analysis is possible at school $A$, where home fluoride concentration was measured alongside Dean Index, gender, and age of each subject, but was not possible at school $B$, where, for logistical reasons, home fluoride concentration was collected on a second visit and not matched to the other variables. All higher order interactions between variables, for example an age-gender interaction or age-genderhome fluoride, were examined but included in the final model only when these interactions contribute to the goodness of fit with statistical significance.

\section{Results}

\subsection{Sorption Kinetics}

Figure 2 shows the relative rate of sorption in continuously stirred reactors, with $2.0 \mathrm{~g}$ of each material in $1 \mathrm{~L}$ artificial groundwater, while $0.5 \mathrm{~mL}$ were withdrawn periodically for analysis. A second order reaction best fits these data and describes the rate of fluoride uptake in pure hydroxyapatite, powdered and sieved to $100-250$ $\mu \mathrm{m}$, suggesting that there are no intra-particle diffusion limitations:

$$
\frac{\mathrm{d} S(t)}{\mathrm{d} t}=k_{2}\left(S_{\text {equil }}-S(t)\right)^{2}
$$

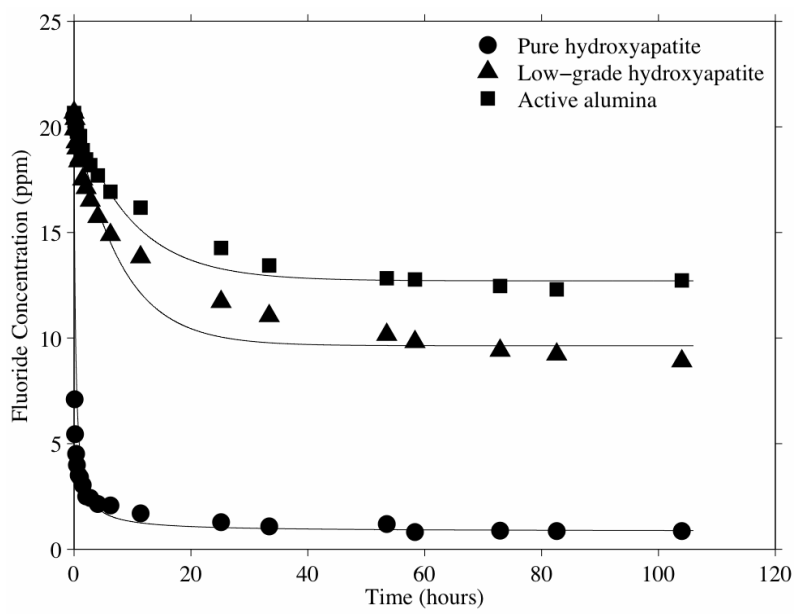

Figure 2. The relative rates of fluoride removal for hydroxyapatite and active alumina in continuously stirred reactors, with $2 \mathrm{~g} / \mathrm{L}$ sorbent and initial fluoride concentration of $20 \mathrm{ppm}$. Lines are best fits to first order reactions for low-grade hydroxyapatite and active alumina, and second order reaction for pure hydroxyapatite.

$$
S(t)=\frac{S_{\text {equil }} t}{\frac{1}{k_{2} S_{\text {equi }}}+t} .
$$

Here, $S(t)$ is the amount of solute sorbed per mass of sorbent at time $t, S_{\text {equil }}$ is the equilibrium sorption, and $k_{2}$ is a rate constant. To determine the equilibrium sorption and rate constant, data is linearized to:

$$
\frac{t}{S(t)}=\frac{1}{k_{2} S_{\text {equil }}^{2}}+\frac{t}{S_{\text {equil }}} \text {. }
$$

For the experiment in Figure 2, MATLAB curve fitting software determined the rate constant at $4.2 \times 10^{-4} \mathrm{Kg}$ $\times \mathrm{mg}^{-1} \cdot \mathrm{hour}^{-1}$ and equilibrium sorption at $9827 \mathrm{mg} \times$ $\mathrm{Kg}^{-1}$, with correlation coefficient, $R^{2}$, equal to 1.00 on the transformed variable $t / S(t)$ versus $t$. After applying this model to a packed filter bed and using density and porosity measurements, one finds that equilibrium is reached within seconds. Provided $C(t)>0$, then the following equation can approximate scaling from $2 \mathrm{~g} / \mathrm{L}$ experiments to a packed filter bed:

$$
C(t)=C_{o}-\rho n S(t) .
$$

If $C_{o}$ is $20 \mathrm{ppm}$ and the bulk density $\rho$ and porosity $n$ are as Table 2 reports, then $C(t)=0$ when $S(t)=C_{o} / \rho n$, which holds at approximately 8.6 seconds. Since the travel time under continuous flow is 80 minutes in the hypothetical filter model below, nearly 560 times longer than 8.6 seconds, and longer during interrupted flow between uses, this justifies an equilibrium assumption for a packed filter bed for pure hydroxyapatite.

Likewise, these data show that reactions with low-grade 
Table 2. Isotherm results and breakthrough predictions using Equations (5), (6), (8) and (9). Water use is set to 5 L per day per capita for a village of 700 people with influent concentrations of $10 \mathrm{ppm}$. Breakthrough calculations considered idealized cylindrical filters with $35 \mathrm{~cm}$ diameter and $2 \mathrm{~m}$ length. Reported figures on active alumina derive from [33], using a simple volume conversion from the referenced filter bed to extrapolate for this hypothetical filter. Cost figures for hydroxyapatite come from field experiences of this research in Jharkhand. This table uses an exchange rate of $47 \mathrm{Rs} / \mathbf{\$}$. The asterisk (*) indicates that pure hydroxyapatite powder was used to obtain an estimate of the maximum theoretical sorption, but that density and porosity estimates came from measurements on the more granular, low-grade hydroxyapatite.

\begin{tabular}{|c|c|c|c|c|c|c|c|c|c|c|}
\hline Sorbent & $\begin{array}{c}\text { BET } \\
\left(\mathrm{m}^{2} / \mathrm{g}\right)\end{array}$ & Isotherm & $m$-or- $a$ & $\log \left(K_{f}\right)-$ or- $S_{m}$ & $\mathbf{R}^{2}$ & $\begin{array}{c}\text { Porosity } \\
n\end{array}$ & $\begin{array}{c}\text { Bulk density, } \\
\rho(\mathrm{Kg} / \mathrm{L})\end{array}$ & Mass (Kg) & $\begin{array}{c}\text { Break-throug } \\
h \text { (days) }\end{array}$ & $\begin{array}{l}\text { Cost of } \\
\text { media }\end{array}$ \\
\hline Pure hydroxy-apatite & 42 & Freundlich & 0.20 & 4.11 & 0.89 & $0.61^{*}$ & $0.34 *$ & 66.9 & 64.1 & n.a. \\
\hline $\begin{array}{l}\text { Low grade } \\
\text { hydroxy-apatite }\end{array}$ & 63.9 & Freundlich & 0.40 & 3.67 & 0.98 & 0.61 & 0.34 & 66.9 & 36.8 & $\begin{array}{l}\text { Rs } 5800 \\
\$ 123.40\end{array}$ \\
\hline Active alumina & 350 & Langmuir & 0.08 & 9.27 & 0.97 & 0.48 & 0.67 & 128.9 & 36.1 & $\begin{array}{c}\text { Rs 38,095 } \\
\$ 425.53\end{array}$ \\
\hline
\end{tabular}

hydroxyapatite and active alumina are fast enough to justify a filter model that neglects kinetics. First order reactions capture the initial reaction rate of active alumina and low-grade hydroxyapatite. These kinetics follow the form

$$
\begin{gathered}
\frac{\mathrm{d} S}{\mathrm{~d} t}=-k_{1}\left(S_{\text {equil }}-S\right), \\
S(t)=S_{\text {equil }}\left(1-\exp \left(-k_{1} t\right)\right) .
\end{gathered}
$$

Although the first-order model does not describe the full data set in Figure 2 accurately, fitting the model to the first 5 hours of data achieves a reasonable estimation of the fast part of the curve and the end point value. MATLAB curve fitting algorithms estimate $k_{1}=-0.15$ hours $^{-1}$ with $S_{\text {equil }}=5929 \mathrm{mg} \times \mathrm{Kg}^{-1}$ for low-grade hydroxyapatite and $k_{1}=-0.12$ hours $^{-1}$ with $S_{\text {equil }}=4239 \mathrm{mg}$ $\times \mathrm{Kg}^{-1}$ for active alumina. The first order kinetic model over-predicts the rate of fluoride sorption in these samples after $\sim 10$ hours, while $C(t)$ approaches $C e$, as shown by the deviation between the fitted line and the data. This deviation indicates that intra-particle diffusion governs the kinetics at that point. Neglecting the intraparticle diffusion and setting $C(t)=0$ when $S(t)=C_{o} / \rho n$, the first-order model predicts that the solution reaches equilibrium at approximately 6 minutes 37 seconds for low-grade hydroxyapatite and at 4 minutes 15 seconds for active alumina. As with pure hydroxyapatite, this is sufficiently fast to justify an equilibrium assumption in a packed filter bed where the travel time is 80 minutes under continuous operation.

\subsection{Sorption Isotherms}

Sorption isotherms illustrate the relative potential for fluoride removal for different materials. Figure 3 shows the sorption isotherm for each material where plastic vials shook for several days to ensure equilibrium, with

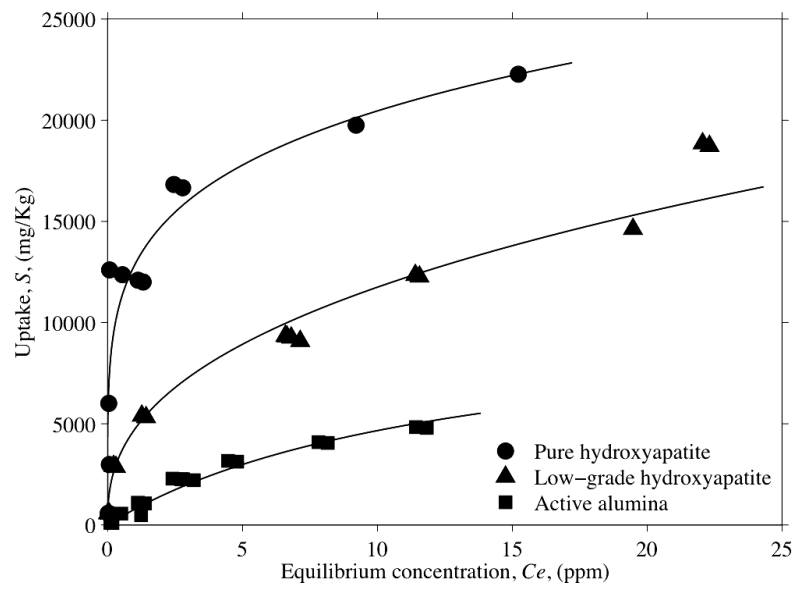

Figure 3. Sorption isotherms at pH 6.5, showing the milligrams of fluoride sorbed per kilogram material in artificial groundwater. Lines are best fits for Freundlich isotherms (hydroxyapatite samples) and Langmuir isotherm (active alumina).

least squares regression curves to Freundlich isotherms (hydroxyapatite) or Langmuir isotherms (active alumina). Freundlich isotherms follow the form

$$
S=K_{f} C e^{m},
$$

where $S$ is again the amount of solute sorbed per mass of sorbent, $\mathrm{Ce}$ is the equilibrium solute concentration, and $K_{f}$ and $m$ are sorption constants. Langmuir isotherms follow the form

$$
S=\frac{a S_{m} C e}{1+a C e},
$$

where $a$ is a material parameter and $S_{m}$ is the maximum sorption capacity. In all cases, software tested a linear, Freundlich, and Langmuir isotherm fit, but Table 2 only reports the best-fit isotherm. All fluoride concentration values derive from ion chromatography measurements (Dionex, column AS12-A) with an eluent of $0.8 \mathrm{mM}$ 
bicarbonate and $2.1 \mathrm{mM}$ carbonate, flowing at $2.0 \mathrm{~mL} /$ min flow with $25 \mathrm{~mA}$ current.

\subsection{Hypothetical Filter Performance and Breakthrough Calculations}

Table 2 summarizes results of sorption isotherms and tabulates hypothetical breakthrough calculations using Equations (5), (6), (8), and (9). These results indicate that fluoride binds to hydroxyapatite in greater amounts than to active alumina when normalizing per unit mass, and binds in even greater amounts when normalizing per unit surface area because active alumina has five to ten times the surface area the hydroxyapatite samples studied here (Table 2). This is not surprising, as active alumina removes fluoride through surface sorption, while hydroxyapatite can remove fluoride in three ways, namely surface sorption, crystal substation [17], and fluorite precipitation , shown below.

$$
\begin{gathered}
\mathrm{Ca}_{5}\left(\mathrm{PO}_{4}\right)_{3}(\mathrm{OH})_{(s)}+\mathrm{F}^{-} \rightarrow \mathrm{Ca}_{5}\left(\mathrm{PO}_{4}\right)_{3}(\mathrm{OH}) \equiv \mathrm{F}^{-} \\
\mathrm{Ca}_{\text {surface }}^{2+}+2 \mathrm{~F}^{-} \rightarrow \mathrm{CaF}_{2(s)} \\
\mathrm{Ca}_{5}\left(\mathrm{PO}_{4}\right)_{3}(\mathrm{OH})_{(s)}+\mathrm{F}^{-} \rightarrow \mathrm{Ca}_{5}\left(\mathrm{PO}_{4}\right)_{3}(\mathrm{OH})_{(1-x)}(\mathrm{F})_{(x)(s)}
\end{gathered}
$$

Here, $0<x<1$.

Table 2 predicts that fluoride breakthrough occurs much earlier in a filter packed with active alumina as compared to one packed with high quality hydroxyapatite, and they predict that breakthrough occurs in about the same time in a filter packed with active alumina as one packed with low quality hydroxyapatite. This study did not attempt to optimize the fluoride removal capacity of low-cost hydroxyapatite, but future research may align the performance of granular, low-cost hydroxyapatite more closely with pure hydroxyapatite powder and consequently achieve large gains in breakthrough times, with values approaching that of Table 2. Another possible line of research to improve the filter performance is to develop high surface area hydroxyapatite particles at low cost, building on knowledge of porous ceramics beads [34], which have high structural integrity and uniformity.

\subsection{Baseline Health Survey in Palamu}

Figure 4 shows the distributions of Dean Index values at all three schools. At the low-fluoride school $(C), 13 \%$ of students scored a Dean Index greater than 1 , in contrast to the high fluoride schools $(A, B)$, where the vast majority of students scored a Dean Index greater than 1 ( $A$ : $78 \%, B: 86 \%)$. The median Dean Index values for the low-fluoride school was 0.5 , while the medians for the high-fluoride schools were 2 and 3 for $A$ and $B$, respectively.

Severe and moderate leg bone bending due to skeletal fluorosis was observed in children at schools $A$ and $B$ (Figure 5) and among adults within the community, but this study did not attempt to quantitatively measure skeletal fluorosis for any sample set.

Students in high fluoride community $A$ show significantly more dental fluorosis than students in community $C$, even when the fluoride concentration in the home water supply of the students in school $A$ is low. Three of five students (60\%) whose home water fluoride concentration fell between 0.8 and 1.8 ppm scored a Dean Index above 1 at school $A$, while only $13 \%$ of students drinking water with slightly less than $1 \mathrm{ppm}$ fluoride at school $C$ developed dental fluorosis above Dean Index values of 1 . This makes students at school $A$ more susceptible to moderate or severe dental fluorosis than students at school $C$, who were exposed to water with a similar fluoride concentration at home. Since a small change in water quality at home is unlikely to cause a higher susceptibility to dental fluorosis, fluoride intake through other sources most likely explains the observation of a high incidence of Dean Index values above 1 among children with low fluoride in their home water supply at school $A$. The water supply at school $A$, measured at 7.1 ppm during January 2009, may be the main fluoride source for these children; on all days they attend school, children drink water at school and consume food cooked with that water, including stews and soups.

A generalized linear regression model identifies a significant age trend and nearly significant interaction between age and home fluoride concentration. After testing the normal distribution of the response variable and identity link function to transform the predictor variables, $g(\mu)$ $=\mu$, and exploring all possible combinations of interaction terms, the analysis demonstrates that the simplest model which best describes the data was:

$$
Y=\beta_{0}+\beta_{1} \text { Age }+\beta_{2} F+\beta_{3} G+\beta_{4}(\text { Age } \times F),
$$

where $Y$ is the Dean Index, $\beta_{0}$ is a fitted constant, $\beta_{i}$ ( $i=1,2,3,4)$ are regression coefficients, Age is the subject age, $G$ is gender, and $F$ is the home fluoride concentration. The $P$-value for this model was 0.01 and Pearson correlation of this regression was 0.89 , with 37 degrees of freedom. Table 3 reports regression coefficients and goodness of fit statistics.

As Figure 6 shows, with select 2-dimensional plots, the main highlights of this regression model are that the Dean Index tends to increase with age and that the home water fluoride concentration plays a more important role as age increases. That is, the model predicts that older 

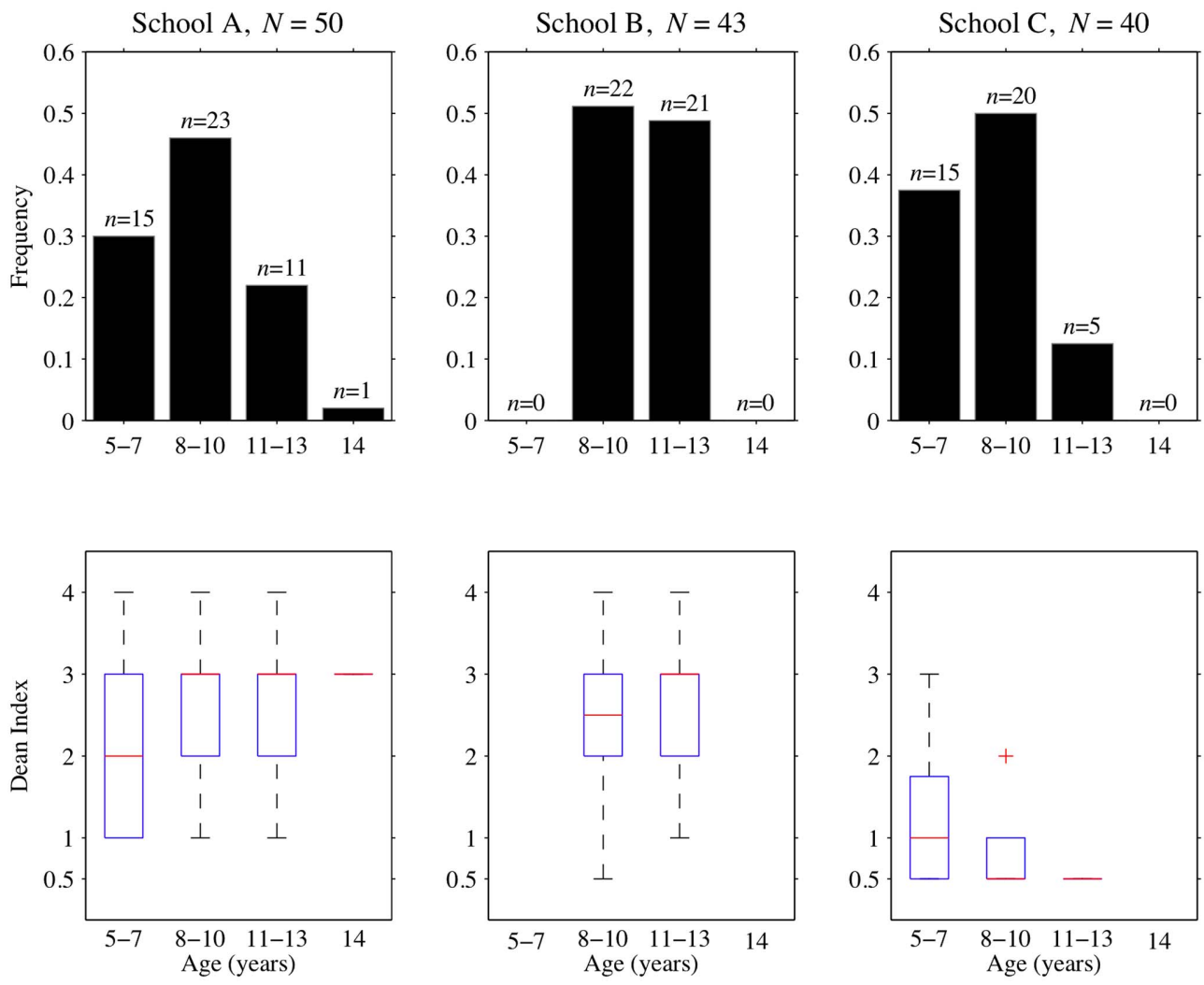

Figure 4. Data from three schools with average village fluoride concentration of (A) 4.7 ppm, (B) 2.3 ppm, and (C) all sources $<1 \mathrm{ppm}$. (top) Histograms showing age distribution for the 3 schools, where $\mathrm{N}$ is the total number of children surveyed. (bottom) Boxplots of Dean Index values at the 3 schools.

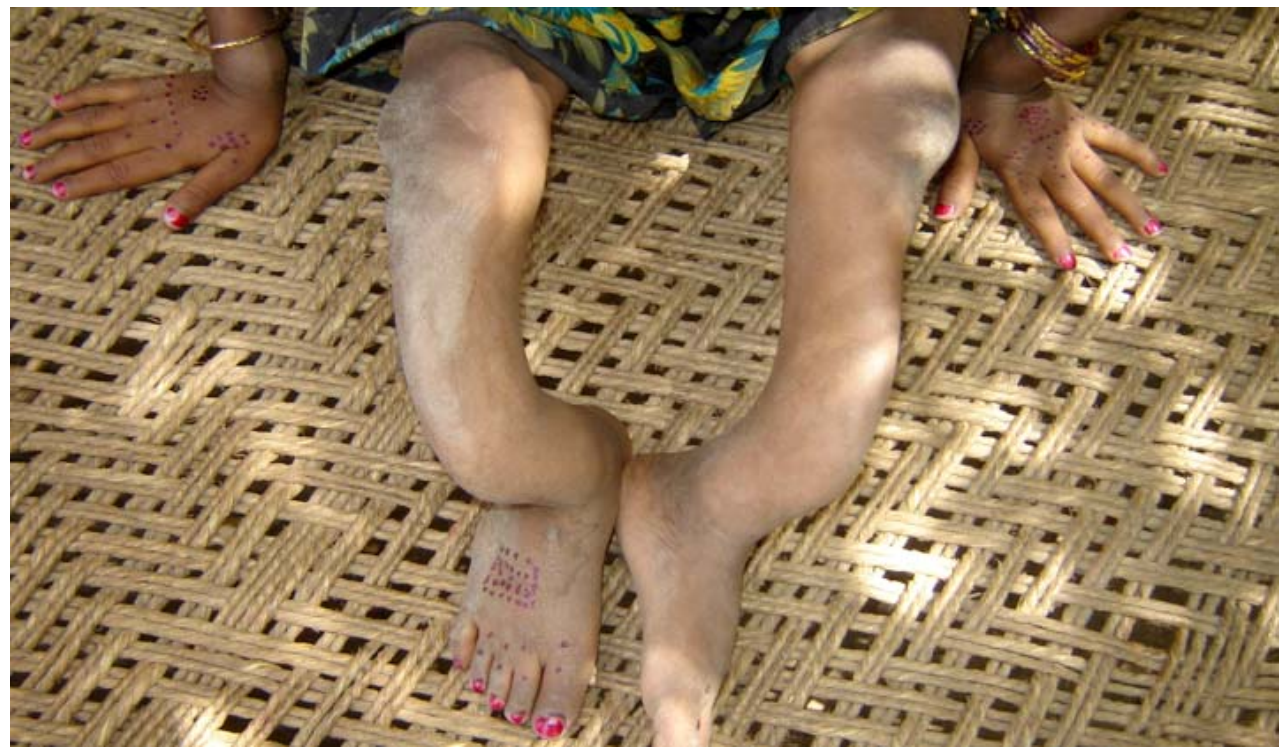

Figure 5. Photograph of girl living within the community of $\operatorname{school} A$ with pronounced bending in the lower leg, a typical "U”-shaped deformity due to skeletal fluorosis.

children who drink high levels of fluoride at home will have higher Dean Index values than counterparts with less fluoride in their home water supply, while the model predicts that high home fluoride concentration does not tend to increase Dean Index values for children below age 9 . As children age from 9 to 11.5 years, a relatively 
Table 3. Results from a generalized linear model fit with normal distribution of the response variable, here the Dean Index, and identity link function. Upper and lower confidence limit reported at $95 \%$. Low $P$-values indicate that the response variable is a good linear predictor of the data, while high values indicate that the response value does not linearly predict the data. The $\boldsymbol{P}$-values and coefficient values in this table indicate that home fluoride concentrations alone poorly predict dental fluorosis, but allowing for the interaction between age and fluoride simultaneously proves to be a good model predictor. Age and gender are both correlated with Dean Index. The model assigned nominal value 1 for females and 0 for males.

\begin{tabular}{|c|c|c|c|c|c|}
\hline Term & Estimate & Std Error & $P$-value & Lower CL & Upper CL \\
\hline$\beta_{0}$ (Intercept) & 0.94 & 0.60 & 0.13 & -0.28 & 2.15 \\
\hline$\beta_{1}$ (Age) & 0.16 & 0.06 & 0.01 & 0.05 & 0.28 \\
\hline$\beta_{2}$ (Fluoride) & 0.01 & .05 & 0.83 & -0.10 & 0.12 \\
\hline$\beta_{3}$ (Gender) & -0.21 & 0.13 & 0.12 & -0.47 & 0.06 \\
\hline$\beta_{4}$ (Age·Fluoride) & 0.05 & 0.03 & 0.08 & -0.01 & 0.11 \\
\hline
\end{tabular}

short time, the model predicts that children exposed to 8 ppm fluoride concentrations in water at home shift from an average of 2.7 to an average of 3.6 Dean Index score, whereas their counterparts exposed to $3 \mathrm{ppm}$ fluoride concentration at home retain an average of 2.7 Dean index during that time period (Figure 6). This indicates that removing fluoride from the student's drinking water will tend to reduce the rate of increase in dental fluorosis in older children and that the Dean Index of children will serve as a fast, sensitive early-warning indicator of health outcomes within just a few years after installing filters.

The model predicts that male students at any age display a higher mean Dean Index value than female students. Exploring for an age-gender interaction suggests that no significant cross-correlation exists $(P=0.45)$, implying that, despite the higher average for boys, the rate of accumulating dental fluorosis is the same in both sexes. Studies on other populations do not always find a correlation with gender and fluorosis [35,36], and in this case there is no age-gender interaction, which suggests that young male children may have higher fluoride exposure or susceptibility at an early age.

\section{Discussion}

\subsection{Filter Cost, Robustness, and Waste Disposal}

The initial cost of hydroxyapatite-based filter beds is roughly $15 \%$ that of active alumina beds (Table 2). However, since the media lasts only a little over a month, regenerating or replacing media incurs a non-negligible cost. Research demonstrates that active alumina can be regenerated at high $\mathrm{pH}[20]$ and other work suggests that regeneration of hydroxyapatite is also possible at high $\mathrm{pH}$, at least in principle, because the ion exchange of fluoride and the hydroxyl group is reversible in strongly basic solutions [37]. However, researchers have not tested the performance of hydroxyapatite over several regeneration cycles, and, more importantly, regeneration will not be cost effective. Assuming that the cost of regeneration is the same for both media, then extrapolating from Sarkar, Gupta et al. [33], while correcting for changes in filter size and holding labor costs constant, one finds that the cost estimate of regeneration is roughly Rs 8000 , a price that exceeds the cost of manufacturing fresh, low-grade hydroxyapatite. Although the price gap shrinks with time, an initial purchase of active alumina and ensuing monthly regeneration remains far more expensive in the long-term than manufacturing and replacing hydroxyapatite each month. In 10 years, these analyses predict that the cost of a hydroxyapatite filter is approximately $70 \%$ that of an active alumina filter, a figure that also holds true at 20 years.

As research on low-cost hydroxyapatite continues, the price may significantly decrease. Ninety-five percent of the cost of manufacturing the low-grade hydroxyapatite samples was in phosphoric acid, and future research can seek less expensive local options for phosphate. Although this acid is costly, the advantage of using phosphoric acid, the method in [30], is that the final product has neutral $\mathrm{pH}$ without salt byproducts. The phosphoric acid used in this study was manufactured from phosphate ore in nearby mines and was purchased from a vendor in Ranchi, the capital of Jharkhand. Similar vendors were present in the small city of Daltonganj, less than $10 \mathrm{~km}$ from the field site, where some adult residents work. Such vendors are common throughout India. Using concentrated phosphoric acid poses some safety risks, but these are not prohibitive, and safety instruction and equipment can mitigate risk. This is true of other local manufacturing processes that involve chemicals, fire, coals, or machinery.

There are several non-economic advantages to using fresh hydroxyapatite over regenerated active alumina. One is that the fluoride uptake capacity of active alumina decreases by 2\% with five regenerations [20]. Extrapolating to 10 regenerations per year implies that the filter will operate at $75 \%$ capacity in just 7 years, indicating that a continuous supply of fresh hydroxyapatite is a more robust solution. The second principal advantage to replacing spent hydroxyapatite with fresh material over regenerating an active alumina filter with caustic solutions is that spent hydroxyapatite media, which is predominantly fluorapatite, is not hazardous and is stable under geologic conditions over a wide range of $\mathrm{pH}$ [38]. 


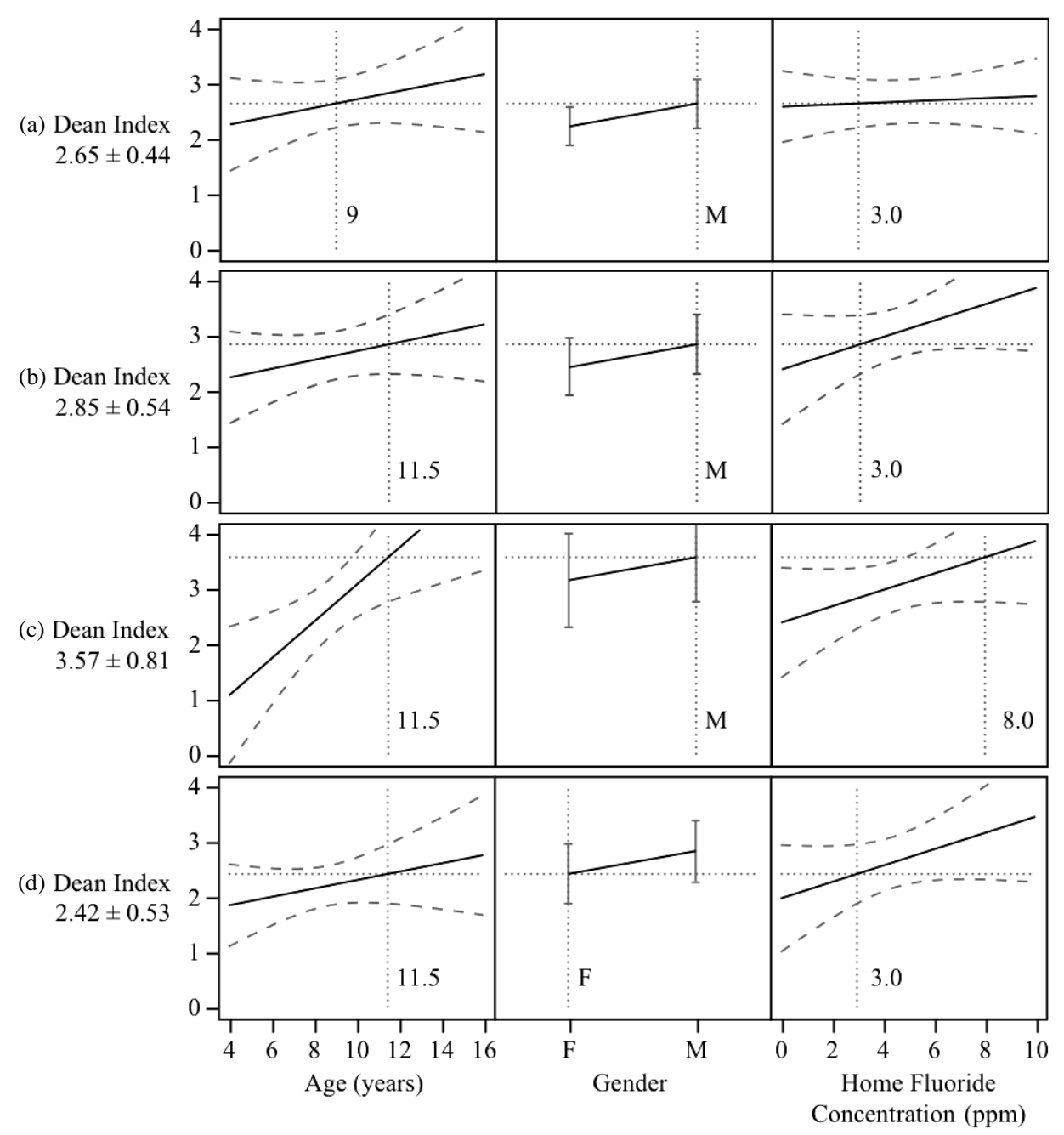

Figure 6. Results from the generalized linear model fit to the Dean Index data in school $\boldsymbol{A}$. Solid lines are regression results, long dashed lines are $95 \%$ confidence intervals, and short dashed lines are present to help illustrate the predicted Dean Index curve for particular values of the explanatory variables. This model predicts that the home fluoride concentration at age 9 does not influence the Dean Index value (a), but as children age the high home fluoride concentration becomes an important predictor of the Dean Index (b verus c). Trends for both sexes are similar, but comparing (b) to (d) one finds an example of the general principle that, for this data set, girls are predicted to have lower Dean Index values.

On the other hand, caustic sludge with high levels of fluoride is much harder to dispose of safely and has a high leaching potential. A third, untested advantage of hydroxyapatite is the potential to remove pathogens much as a slow or rapid sand filter removes pathogens, when biofilms form on on surfaces, a potential that future work should explore.

\subsection{Using the Dean Index as Part of a Fluoride Control Strategy}

Rapid assessment of dental fluorosis provides a good estimate of the community health with respect to fluoride and readily integrates into a fluoride intervention strategy when communities have access to the results of health surveys. In contrast to dental fluorosis, the full spectrum of skeletal fluorosis symptoms is difficult to observe without detailed medical examinations, including x-rays, and is even more difficult to quantify rapidly as this entails physical tests [10,25,26]. Dental fluorosis is readily observed, and a number of epidemiological tools can easily quantify this variety of fluorosis [32]. While a dental fluorosis survey will not fully capture the public health impact of high levels of fluoride, population estimates of the two varieties of fluorosis should roughly correlate, implying that measures of dental fluorosis can serve as a proxy and early warning indicator for the less visible skeletal problems. Skeletal fluorosis problems often take many years to manifest, but the results of this study indicate that the Dean Index increases rapidly with 
age in children, suggesting that age-based population averages can serve as a benchmark for success in fluoride intervention programs if tracked over time. Such information can empower communities by serving as a public indication of success or failure of the water treatment, giving a clear reference with which communities can leverage water service providers who are not properly maintaining the filter.

\subsection{Implementing a Defluoridation Strategy in Jharkhand}

Despite efforts to manage a defluoridation program, fluoride levels in drinking water remain high in Palamu today. In 2005, the Jharkhand state government installed active alumina filters on hand pumps to defluoridate drinking water in some parts of the Palamu district, an approach that the WHO endorses [18]. But as the above results show, active alumina is not an ideal substrate for fluoride removal, both in terms of removal capacity and cost. Furthermore, fluoride ions will increase the solubility of aluminum, especially at low $\mathrm{pH}$ [39], which poses a health risk. Numerous studies demonstrate that soluble aluminum is a neurotoxin [40] and some research even links aluminum in the brain to Alzheimer's disease, although that link is controversial [41,42]. Furthermore, Table 1 demonstrates that low-grade hydroxyapatite is by far the cheaper solution for treating water. It is at least as effective as active alumina, possibly more so as manufacturing techniques approach the theoretical limit of sorption onto high-quality hydroxyapatite. Considering the putative negative health effects of active alumina, the lower performance of active alumina vis a vis hydroxyapatite, and taking the relative cost of each material into account, the evidence stacks in favor of choosing hydroxyapatite.

Regardless of what was inside the filters at the outset of this defluoridation program, the filters in Palamu today do not function properly because there was no programmatic follow up. Field surveys conducted as part of this research found outflow fluoride concentration from the filter at School $A$ nearly identical to influent concentration today (inflow $=7.8 \mathrm{ppm}$; outflow $=7.1 \mathrm{ppm}$ ), and the widespread dental fluorosis among the students at that school suggests that, over the long term, the filters have not significantly helped residents' health. In January 2009, local schoolteachers reported that no official visited the school to check on the filter in three years. Nearby residents removed several filters from village hand pumps due to clogging. Many filters lay broken and dismantled throughout the district due to clogging or theft.

Why did this system fail? The initial maintenance strategy placed all responsibility on the state Drinking Water and Sanitation Department, where the duty of routine maintenance fell to junior level engineers, including monitoring water chemistry and exchanging spent media for market-available fresh media. Thus, failure to succeed implies that senior level officials either could not or chose not to ensure their juniors' compliance with that duty. This is unsurprising as the World Bank ranks corruption in Jharkhand state high and finds that exclusion of the poor from government programs is especially rampant there as compared to the rest of India [27]. By early 2009, the state had seen six political crises resulting in changes of leadership since its formation in September of 2000, making it difficult to execute administrative duties [43]. Adding to these difficulties, government officials fear for their safety in Palamu and may be unable to work safely there, as that district is well known as a hotspot of extremist political violence [27]. Extremist groups, known locally as MCC or Naxalites, regularly attack officials, especially police officers $[27,44]$.

Palamu villagers lacked autonomy under the initial defluoridation management scheme. The state government possessed all technical knowledge of the filters, making it impossible for residents to do their own maintenance or purchase their own supplies when outsider maintenance schemes fail. Active alumina may have been too expensive, regardless, because Palamu is extremely poor, with 23\% food insufficiency (Table 1). Although field interviews conducted with this research revealed that many residents knew of the fluoride problem and actively used government filters in an effort to protect their health, suggesting they might have properly maintained the units given the opportunity, residents reported that they did not know how to fix broken units and that complaining to local representatives did not result in action.

The confluence of all of the above factors resulted in systematic program failure. Posing these factors in a more a general framework, two categories of explanations for the program failure emerge: 1) a lack of accountability on the party responsible for filter maintenance and 2) inadequate communication channels and leverage between stakeholders and the party responsible for filter maintenance.

There are successful alternative approaches to rural water supply treatment and systems management. One relevant example is a highly successful arsenic treatment program in the neighboring state of West Bengal, where universities, local NGOs, and international NGOs coordinated a management program that relies on direct stakeholder involvement $[33,45]$. As discussed above, the arsenic problem is similar to the fluoride problem except that the amount of fluoride tends to be much higher than arsenic. The program in West Bengal shows 
sustained success for over 8 years, treating the water of 150,000 people in agricultural villages and in larger towns and a similarly patterned fluoride program may also prove viable.

Each player in the West Bengal program played an important role in the success of the program today. Bengal Engineering and Science University in India and Lehigh University in the United States provided the initial design, testing, and deployment, and helped coordinate training with the local NGO. A US-based NGO, Water for People, provided the funding for the initial filter costs. A local NGO, formed specifically for this task, served to make the initial approach to a community with an arsenic problem and later assists with training and education. Today, the community plays a direct role via an elected village water council who appoints and pays a caretaker to test and maintain the filter quality. Families that want to drink arsenic-free water pay a monthly fee to the council, who then uses the money to pay the caretaker and materials cost.

We posit that the West Bengal arsenic treatment program is successful because of robust accountability mechanisms. The primary responsibility of filter maintenance falls to the caretaker, who reports to the democratically selected village water committee, which pays the caretaker and holds the caretaker accountable. Village water committees are, in turn, accountable to families that opt-in to the water program and pay monthly dues. The caretaker works directly with an impartial local NGO with the means to publicize problems, further ensuring accountability.

Other program models have proven effective in rural India for similar problems. One public-public-partnership (PUP) in the state of Tamil Nadu leveraged engineering expertise from a public water supply board by allowing stakeholder participation. The community participated in initial decisions at town hall style meetings and later provided investment capital for water projects, working closely with engineers during infrastructure implementation, ensuring accountability of the water supply board. The outcome of this PUP was reduced running costs over three years, increased coverage, and improved services for some 51,000 households.

A successful program to defluoridate water will take components from the above examples and include regular health monitoring. Community participation is at the center of this proposed program, embodied in the village level water committees, which integrate well with the Jharkhand state government's plan to promote village health and sanitation committees throughout the state as put forth by the Dept. of Health and Family Welfare [46]. Figure 7 demonstrates how this program can be constructed in Jharkhand to achieve accountability and stakeholder involvement. The main feature of Figure $\mathbf{7}$ is the presence of robust accountability mechanisms, checks and balances on responsible parties, wherein the players are interchangeable. For example, large private companies, start-up entrepreneurs, or local NGOs could play the role of filter media manufacturer so long as the stakeholders manage some degree of payment for such services, much like the programs in Tamil Nadu or West Bengal. Setting up flexible systems with robust accountability mechanisms like these examples allows water supply to be demand-responsive, expanding or contracting in accordance with the end-user's needs, thereby empowering local populations.

A filter based on hydroxyapatite is a practical solution to the fluoride problem in Jharkhand that fits well with the above conceptual model for filter management. A simple valve on each filter can divert water not used for cooking and drinking, helping to minimize treated water volume and prolong filter life. This approach was used on the government-installed active aluminum filters. At 10 ppm fluoride groundwater, a community of 700 has the potential to treat all of their drinking water for over one month, longer if the groundwater concentration is lower, at a cost of only 5800 Rs, or 8.3 Rs per head, which is easily affordable by community standards; schoolteachers in Palamu report that the government will spend a total of 60 Rs per head for school lunches over 30 days. Not only is hydroxyapatite a cheap option, this work demonstrates that hydroxyapatite manufacturing is unsophisticated and easy to replicate, which means that rural entrepreneurs can make a livelihood out of importing raw materials from larger town markets to produce hydroxyapatite locally, replacing media every month or few months, thereby stimulating the local economy. Distribution of such a technology, when implemented under the conceptual model above, can grow organically in response to community needs.

Of equal importance to an appropriate technology, a system of health data collection and review must be in place to ensure accountability and to identify areas where fluorosis interventions do not succeed. As the results of this research show, the age-wise ranking of the Dean Index within the community is a sensitive indicator of dental fluorosis. Accordingly, an infrastructure must be in place to track the Dean Index at regular intervals and then report this information to the health department and stakeholders, i.e. the end-users. Information should be gathered at the village level across the entire district. One possible means to perform this task is to piggy-back such data collection on activities of the village committees (Figure 7), perhaps employing committee members or paying third-parties to collect Dean Index scores, collaborating with agencies outside the village, shown sche- 


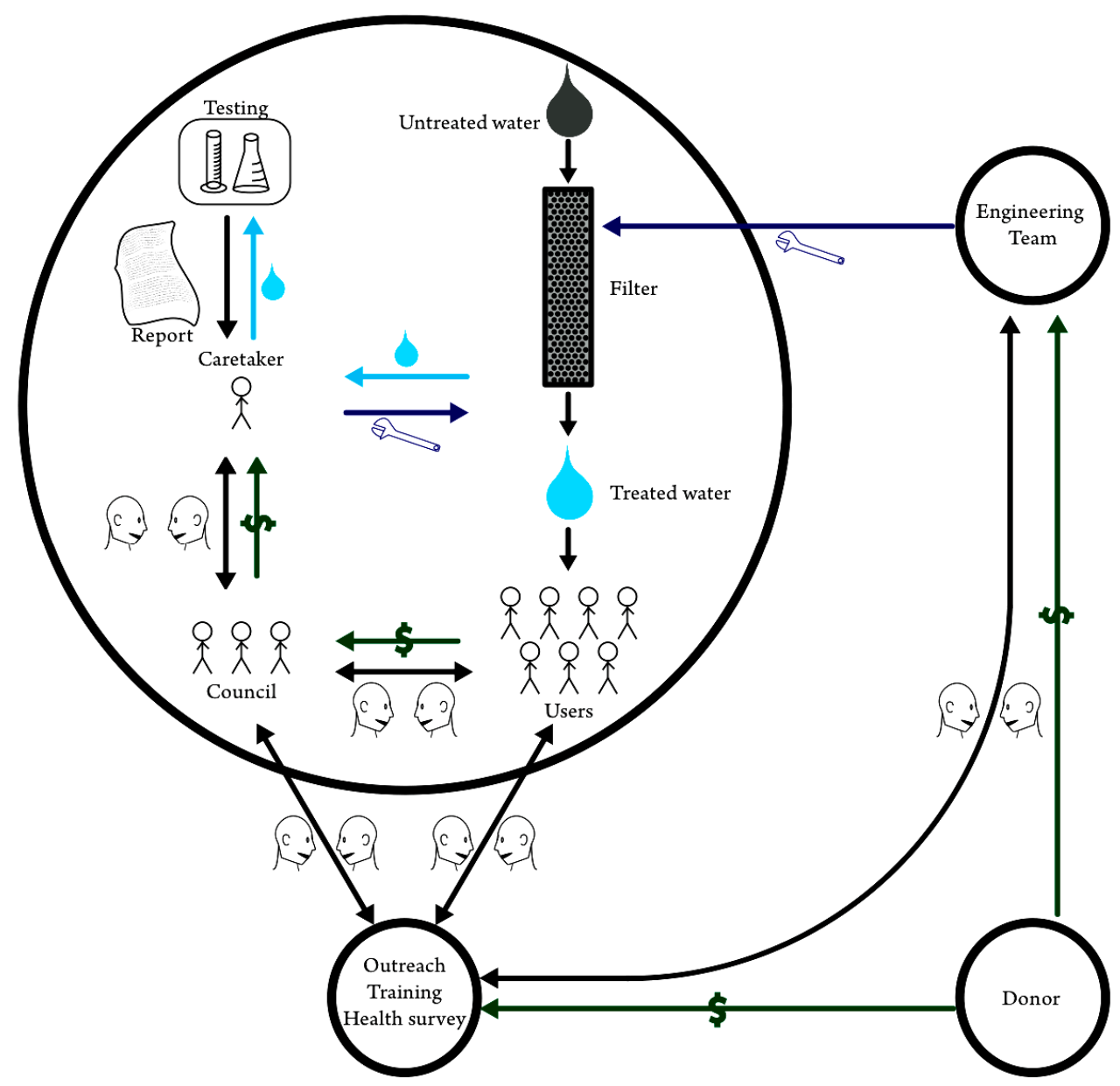

Figure 7. A successful community water treatment management program possesses ample opportunities for dialogue between parties, shown schematically by talking heads, financial leverage between the stakeholders and the caretaker, and impartial outside assistance from the design team and an NGO.

matically in Figure 7 as the black circle. The Dean Index is fast to assess and surveyors with no background easily learn to accurately measure it, making the Dean Index an appropriate health metric for the scheme proposed here. Geographic Information Systems (GIS) records containing Dean Index values tracked over time, which health department officials can maintain at the district level, will show problem areas or areas with successful fluoride interventions in a format easily understandable to stakeholders, engineers, and high level administration alike. Other examples from India suggest that infrastructure for such an information system can be developed and effectively deployed to coordinate public health interventions $[47,48]$. Once gathered at the village level across the entire district, the health department and the stakeholders can point to a concrete result, the Dean Index, to validate the work of the water intervention teams and village level caretakers and to motivate higher performance. Thus, community-wide measures of the Dean Index can ensure checks and balances between responsible parties, and help promote overall health awareness.

\section{Conclusions}

Fluoride in drinking water is one of the most important emerging problems in the rural water supply of developing countries and needs an effective, sustainable treatment solution. This paper demonstrates that locally synthesized hydroxyapatite in Jharkhand, India is an effective, inexpensive option for defluoridation that is superior to active alumina, the material currently used to remove fluoride in Jharkhand. Equilibrium, advective 1-d transport models predict that breakthrough will occur at the same time or longer with varieties of hydroxyapatite as compared to active alumina. This paper also provides the basis for future health monitoring of the population and proposes a framework for implementing such long-term health surveillance, an essential component of any water intervention. Field surveys found that the Dean Index values among children in two communities with 
high fluoride in the water supply were higher than a similar community with low drinking water fluoride levels, and that the Dean Index tended to increase with age, especially for children with high home water source fluoride concentrations. This result, which may be generalizable to other populations, suggests that the Dean Index of children at these schools in Jharkhand can provide a rapid, sensitive indication of the early success of any defluoridation programs. The combination of the ease of health monitoring via the Dean Index and the simplicity of hydroxyapatite synthesis bodes well for community-driven water systems management that, as other work demonstrates, are successful and sustainable solutions. Future research targets in Jharkhand include refining low-grade hydroxyapatite to optimize cost and performance, and implementing these strategies at the community level.

\section{Acknowledgements}

The Dean Index surveys were performed by researchers of Environmental Science and Engineering Group, Birla Institute of Technology, Mesra, Ranchi, India. Free and informed consent of the participants was obtained by researchers following BIT ethical guidelines after review by faculty and the Coordinator Environmental Science and Engineering Group, Birla Institute of Technology, Mesra, Ranchi, India. The authors would like to thank the following individuals for support during this research: Dr. M. S. Nathawat, Dr. Usha Jha, Mr. Kirti Avishek, Dr. A. C. Pandey, Mr. Hemant Kumar Singh, Ms. Neeta Kumari, Ms. Mili Ghosh, Mr. Amit Kumar, Mr. G. Tiwari, Mr. Ashish Singh, Mr. Rajeev Singh, and Mr. Raghuveer Vinukollu. Pure hydroxyapatite was provided by Prof. Ange Nzihou, from the École des Mines d'Albi-Carmaux, France. Funding for the visit of Prof. Pathak to Princeton University was provided by the Princeton Institute for International and Regional Studies. Funding for this research was provided by a grant from the Environ Foundation and Princeton University's Grand Challenges initiative. Support for L. MacDonald was provided by Princeton Environmental Institute's program in Science, Technology and Environmental Policy.

\section{References}

[1] United Nations Human Development Programme, "Beyond Scarcity: Power, Poverty and the Global Water Crisis," Human Development Report, United Nations Human Development Programme, Washington, 2006, p. 440.

[2] Department of Economic and Social Affairs, "World Urbanization Prospects: The 2007 Revision,” Department of Economic and Social Affairs, New York, 2008.

[3] S. Ayoob and A. K. Gupta, "Fluoride in Drinking Water:
A Review on the Status and Stress Effects," Critical Reviews in Environmental Science and Technology, Vol. 36, No. 6, 2006, pp. 433-487. doi:10.1080/10643380600678112

[4] L.S. Yang, et al., "Developing Environmental Health Indicators as Policy Tools for Endemic Fluorosis Management in the People's Republic of China," Environmental Geochemistry and Health, Vol. 25, No. 3, 2003, pp. 281-295. doi:10.1023/A:1024543819240

[5] R. Chandrajith, et al., "Fluoride in Ceylon Tea and Its Implications to Dental Health," Environmental Geochemistry and Health, Vol. 29, No. 5, 2007, pp. 429-434. doi:10.1007/s10653-007-9087-z

[6] M. L. Gomez, M. T. Blarasin and D. E. Martinez, “Arsenic and Fluoride in a Loess Aquifer in the Central Area of Argentina,” Environmental Geology, Vol. 57, No. 1, 2009, pp. 143-155. doi:10.1007/s00254-008-1290-4

[7] G. Pathak, M. S. Nathawat and U. Jha, "A Comprehensive Survey on the Water Quality of Vishrampur, Chainpur, Pandu \& Daltonganj Block of Palamau District \& Bhaw Nathpur, Ranka, Bhandaria, Kharanndhi, Nagar, Maghiav of Garwa District with Focus on Fluoride," United Nations Children's Fund, Ranchi, 2005.

[8] R. Tekle-Haimanot, et al., "The Geographic Distribution of Fluoride in Surface and Groundwater in Ethiopia with an Emphasis on the Rift Valley," Science of the Total Environment, Vol. 367, No. 1, 2006, pp. 182-190. doi:10.1016/j.scitotenv.2005.11.003

[9] B. C. Bates, et al., "Climate Change and Water," Technical Paper of the Intergovernmental Panel on Climate Change, IPCC Secretariat, Geneva. 2008, p. 210.

[10] A. L. Khandare, R. Harikumar and B. Sivakumar, "Severe Bone Deformities in Young Children from Vitamin D Deficiency and Fluorosis in Bihar-India," Calcified Tissue International, Vol. 76, No. 6, 2005, pp. 412-418. doi:10.1007/s00223-005-0233-2

[11] M. T. Alarcon-Herrera, et al., "Well Water Fluoride, Dental Fluorosis, and Bone Fractures in the Guadiana Valley of Mexico," Fluoride, Vol. 34, No. 2, 2001, pp. 139-149.

[12] E. B. Bassin, et al., "Age-Specific Fluoride Exposure in Drinking Water and Osteosarcoma (United States)," Cancer Causes \& Control, Vol. 17, No. 4, 2006, pp. 421-428. doi:10.1007/s10552-005-0500-6

[13] J. A. Varner, et al., "Chronic Administration of AlumiNum-Fluoride or Sodium-Fluoride to Rats in Drinking Water: Alterations in Neuronal and Cerebrovascular Integrity," Brain Research, Vol. 784, No. 1-2, 1998, pp. 284-298. doi:10.1016/S0006-8993(97)01336-X

[14] X.Z. Xiong, et al., "Dose-Effect Relationship between Drinking Water Fluoride Levels and Damage to Liver and kidney Functions in Children," Environmental Research, Vol. 103, No. 1, 2007, pp. 112-116. doi:10.1016/j.envres.2006.05.008

[15] B. K. Shrivastava and A. Vani, "Comparative Study of Defluoridation Technologies in India," Asian Journal of Experimental Sciences, Vol. 23, No. 1, 2009, pp. 269274. 
[16] K. Ravindra and V. K. Garg, "Hydro-Chemical Survey of Groundwater of Hisar City and Assessment of Defluoridation Methods Used in India," Environmental Monitoring and Assessment, Vol. 132, No. 1-3, 2007, pp. 33-43. doi:10.1007/s10661-006-9500-6

[17] X. Fan, D. J. Parker and M. D. Smith, “Adsorption Kinetics of Fluoride on Low Cost Materials,” Water Research, Vol. 37, No. 20, 2003, pp. 4929-4937. doi:10.1016/j.watres.2003.08.014

[18] WHO, “Guidelines for Drinking Water Quality,” World Health Organization, Geneva, 2006.

[19] R. K. Daw, "Experiences with Domestic Defluoridation in India," Proceeedings of the 30th WEDC International Conference on People-Centered Approaches to Water and Environmental Sanitation, Vientiane, 25-28 October 2004, pp. 467-473.

[20] S. Ghorai and K. K. Pant, "Equilibrium, Kinetics and Breakthrough Studies for Adsorption of Fluoride on Activated Alumina," Separation and Purification Technology, Vol. 42, No. 3, 2005, pp. 265-271. doi:10.1016/j.seppur.2004.09.001

[21] T. F. Lin and J. K. Wu, "Adsorption of Arsenite and Arsenate within Activated Alumina Grains: Equilibrium and Kinetics," Water Research, Vol. 35, No. 8, 2001, pp. 2049-2057. doi:10.1016/S0043-1354(00)00467-X

[22] T. Aoba, "The Effect of Fluoride on Apatite Structure and Growth," Critical Reviews in Oral Biology \& Medicine, Vol. 8, No. 2, 1997, pp. 136-153. doi:10.1177/10454411970080020301

[23] C. S. Sundaram, N. Viswanathan and S. Meenakshi, "Defluoridation Chemistry of Synthetic Hydroxyapatite at nano Scale: Equilibrium and Kinetic Studies,” Journal of Hazardous Materials, Vol. 155, No. 1-2, 2008, pp. 206215. doi:10.1016/j.jhazmat.2007.11.048

[24] B. H. Singer and M. C. de Castro, "Bridges to Sustainable Tropical Health," Proceedings of the National Academy of Sciences of the United States of America, Vol. 104, No. 41, 2007, pp. 16038-16043. doi:10.1073/pnas.0700900104

[25] J. Cao, et al., "Brick Tea Fluoride as a Main Source of Adult Fluorosis," Food and Chemical Toxicology, Vol. 41, No. 4, 2003, pp. 535-542. doi:10.1016/S0278-6915(02)00285-5

[26] S. Godfrey, et al., "Health-Based Risk Targets for Fluorosis in Tribal Children of Rural Madhya Pradesh, India," 32nd WEDC International Conference: Sustainable Development of Water Resources, Water Supply and Environmental Sanitation, Colombo, 2006.

[27] B. Sen, R. Khanna and K. Kapoor, “Jharkhand: Addressing the Challenges of Inclusive Development,” Report No. 36437-IN, The World Bank, 2007.

[28] A. K. Singh, et al., "Major Ion Chemistry, Weathering Processes and Water Quality Assessment in Upper Catchment of Damodar River Basin, India,” Environmental Geology, Vol. 54, No. 4, 2008, pp. 745-758. doi:10.1007/s00254-007-0860-1

[29] B. Das, et al., "Fluoride and Other Inorganic Constituents in Groundwater of Guwahati, Assam, India,” Current Science, Vol. 85, No. 5, 2003, pp. 657-661.

[30] C. Verwilghen, et al., "Preparation of High Specific Surface Area Hydroxyapatite for Environmental Applications," Journal of Materials Science, Vol. 42, No. 15, 2007, pp. 6062-6066. doi:10.1007/s10853-006-1160-y

[31] D. C. Sheng and D. W. Smith, “Analytic Solutions to the Advective Contaminant Transport Equation with NonLinear Sorption," International Journal for Numerical and Analytical Methods in Geomechanics, Vol. 23, No. 9, 1999, pp. 853-879. doi:10.1002/(SICI)1096-9853(19990810)23:9<853::AIDNAG993>3.0.CO;2-Q

[32] R. G. Rozier, "Epidemiologic Indices for Measuring the Clinical Manifestations of Dental Fluorosis: Overview and Critique," Advances in Dental Research, Vol. 8, No. 1, 1994, pp. 39-55.

[33] S. Sarkar, et al., "Community-Based Wellhead Arsenic Removal Units in Remote Villages of West Bengal, India,” In: S. Ahuja, Ed., Arsenic Contamination of Ground Water: Mechanism, Analysis, and Remediation, Wiley, Hoboken, 2008, pp. 305-327. doi:10.1002/9780470371046.ch13

[34] A. Akash, "Process for Making Ceramic, Mineral, and Metal Beads from Powder,” U.S. Patent, 2009, p. 7.

[35] E. Michel-Crosato, M. G. Biazevic and E. Crosato, "Relationship between Dental Fluorosis and Quality of Life: A Population Based Study,” Brazilian Oral Research, Vol. 19, No. 2, 2005, pp. 150-155. doi:10.1590/S1806-83242005000200014

[36] B. Shomar, et al., "Fluorides in Groundwater, Soil and Infused Black Tea and the Occurrence of Dental Fluorosis among School Children of the Gaza Strip,” Journal of Water and Health, Vol. 2, No. 1, 2004, pp. 23-35.

[37] C. Chairat, et al., "Fluorapatite Surface Composition in Aqueous Solution Deduced from Potentiometric, Electrokinetic, and Solubility Measurements, and Spectroscopic Observations," Geochimica et Cosmochimica Acta, Vol. 71, No. 24, 2007, pp. 5888-5900. doi:10.1016/j.gca.2007.09.026

[38] C. Chairat, et al., "Kinetics and Mechanism of Natural Fluorapatite Dissolution at 25 Degrees C and pH from 3 to 12," Geochimica et Cosmochimica Acta, Vol. 71, No. 24, 2007, pp. 5901-5912. doi:10.1016/j.gca.2007.08.031

[39] B. D. Turner, P. Binning and S. L. S. Stipp, "Fluoride Removal by Calcite: Evidence for Fluorite Precipitation and Surface Adsorption," Environmental Science \& Technology, Vol. 39, No. 24, 2005, pp. 9561-9568. doi:10.1021/es0505090

[40] R. A. Yokel, "The Toxicology of Aluminum in the Brain: A Review,” Neurotoxicology, Vol. 21, No. 5, 2000, pp. 813-828.

[41] C. Exley, “Aluminum and Alzheimer's Disease," The Journal of Alzheimer's Disease, Vol. 3, No. 6, 2001, pp. 551-552.

[42] E. T. Jansson, "Aluminum Exposure and Alzheimer's Disease,” The Journal of Alzheimer's Disease, Vol. 3, No. 
6, 2001, pp. 541-549.

[43] Anonymous, "President Rule Follows Major Political Crisis in Jharkhand," 2009.

http://news.outlookindia.com/item.aspx?652106

[44] Anonymous, "Maoists Release Train with 700 Passengers in East Indian State," PTI News Agency, New Delhi, 2009.

[45] S. Sarkar, et al., "Arsenic Removal from Groundwater and Its Safe Containment in a Rural Environment: Validation of a Sustainable Approach," Environmental Science \& Technology, Vol. 42, No. 12, 2008, pp. 4268-4273.

[46] State Health Mission, "Programme Implementation Plan 2006-2012,” 2008. http://www.mp.gov.in/health/nrhm/pip-nrhm.pdf

[47] A. Srivastava, et al., "Identification of Malaria Hot Spots for Focused Intervention in Tribal State of India: A GIS Based Approach,” International Journal of Health Geographics, Vol. 8, No. 30, 2009. doi:10.1186/1476-072X-8-30

[48] S. Ramani, et al., "Geographic Information Systems and Genotyping in Identification of Rotavirus G12 Infections in Residents of an Urban Slum with SubSequent Detection in Hospitalized Children: EmerGence of G12 Genotype in South India,” Journal of Clinical Microbiology, Vol. 45, No. 2, 2007, pp. 432-437. doi:10.1128/JCM.01710-06 